\title{
The Michigan BioTrust for Health: Using Dried Bloodspots for Research to Benefit the Community While Respecting the Individual
}

\author{
Denise Chrysler, Harry McGee, Janice Bach, Ed Goldman, and
} Peter D. Jacobson

$\mathrm{T}$ The Michigan Department of Community Health $(\mathrm{MDCH})$ stores almost 4 million dried blood spot specimens (DBS) in the Michigan Neonatal Biobank. ${ }^{1}$ DBS are collected from newborns under a mandatory public health program to screen for serious conditions. ${ }^{2}$ At 24 to 36 hours of age, a few drops of blood are taken from the baby's heel and placed on a filter paper card. The card is sent to the state public health laboratory for testing. After testing, MDCH retains the spots indefinitely for the personal use of the patient and also, pursuant to a 2000 law, ${ }^{3}$ for possible research.

DBS have been used in a variety of health research studies. Various biomarkers (e.g., DNA, RNA, and environmental contaminants) can be isolated and studied. The MDCH collection of DBS is comprised of entire birth cohorts dating back to 1984 allowing longitudinal linkages to other population-based data, such as the statewide cancer registry and vital records. For example, a future study could examine DBS to assess pollutants in the blood of newborns from 1984 to present. In this article, we discuss interrelated legal and ethical questions that are fundamental to making DBS available for research. We further discuss the "charitable trust" " model to balance public benefits with respect for individuals whose DBS are used for research.
Recognizing the research value of these stored DBS, in $2008 \mathrm{MDCH}$ created the Michigan BioTrust for Health (Michigan BioTrust) in collaboration with Michigan State University, University of Michigan, Wayne State University, and the Van Andel Institute. The Michigan BioTrust makes DBS specimens and related health data available for research to benefit public health. Such research can advance efforts to develop new disease prevention strategies, diagnostic tests, and treatments for diseases. The Michigan BioTrust's mission is the following: (1) to protect the DBS; (2) to maximize their research utility by creating a biorepository to store them indefinitely under optimal conditions; (3) to promote their research use; (4) to facilitate the retrieval of specific specimens; and (5) to link these specimens with other statewide data, while ensuring patient confidentiality and quality research

Creating the Michigan BioTrust was neither fast nor easy. Community engagement, public education, and ethical oversight were, and still are, key components. A Steering Committee and other workgroups grappled with legal, ethical, scientific and policy issues, including the basic issue of DBS ownership. To consider ownership issues and the nature and scope of MDCH's authority to provide DBS for research, $\mathrm{MDCH}$ con-

Denise Chrysler, J.D., provided legal support for the Michigan BioTrust for Health initiative as the Public Health Legal Director of the Public Health Administration at Michigan Department of Community Health. She is now the Director of the Public Health Law Network, Mid-States Region, at the University of Michigan School of Public Health. Harry McGee, M.P.H., served as the Administrator of the Institutional Review Board at Michigan Department of Community Health. He is now an Assistant Professor in Michigan State University's Office of Regulatory Affairs Human Research Protection Program and chairs the Social/ Behavioral IRB. Janice Bach, M.S., is the State Genetics Coordinator and Manager of the Genomics and Genetic Disorders Section at Michigan Department of Community Health. Ed Goldman, J.D., is an Associate Professor in the University of Michigan Department of ObGyn and President of the Michigan Neonatal Biobank Board of Directors. Peter D. Jacobson, J.D., M.P.H. is the Director of the Center for Law, Ethics, and Health at the University of Michigan School of Public Health. 
vened a roundtable of legal, ethical, public health, and research representatives.

Michigan's Public Health Code ${ }^{5}$ does not address ownership of DBS. It does address their control and require $\mathrm{MDCH}$ to establish policies on retention and destruction. DBS may be used for research as long as the research is conducted in a manner that preserves the confidentiality of the subjects and complies with regulations to protect human subjects from research risks. ${ }^{6}$ There is no direct mention of control by the individual, nor mention of individual consent or dissent to use their DBS for research. MDCH is required to include a statement in its newborn screening educational pamphlet that DBS may be used for research. Research is recognized as a public health function and, as a result, $\mathrm{MDCH}$ is empowered to promote and support research to improve the health of communities and Michigan's citizens, and to use or provide data to benefit the public. ${ }^{7}$ Case law regarding ownership and control generally holds that an individual has no ownership interest in tissue samples once they are collected. Cases in California, ${ }^{8}$ Florida, ${ }^{9}$ and Missouri, ${ }^{10}$ indicate that donated tissue belong to the recipient, suggesting that blood leftover from the Michigan newborn screening program belongs to the MDCH. However, since screening is mandatory, parents had not knowingly donated the leftover DBS. Further, regardless of ownership, there are ethical and regulatory requirements for consent to research and a fundamental right to withdraw from research. ${ }^{11}$

The roundtable concluded that under Michigan law, MDCH has "qualified ownership" in DBS collected for newborn screening, and that MDCH exercises control for the benefit of the child and the public. Due to this "qualified ownership," MDCH is required to act as a fiduciary.

The roundtable's charge included deliberating on the laws governing the use of DBS for research. After agreeing on what $i s$ explicitly allowable by law, the more difficult ethical question of what should be done within these legal parameters was addressed. However, lines between "law" and "ethics" were blurred by laws that require application of ethical principles, such as federal regulations governing human research subjects. ${ }^{12}$ Moreover, "qualified ownership" is more difficult to define than simple legal ownership, requiring ethical concerns to be considered when defining MDCH's authority and responsibilities.

Scholarship on charitable trusts - i.e., David Winickoff and Richard Winickoff's "The Charitable Trust as a Model for Genomic Biobanks"13 - served as the touchstone for designing the Michigan BioTrust. In fact, this "trust" relationship was incorporated from the beginning of the project by including the term
"BioTrust" in the project's name, to denote MDCH's relationship to the public as a trustee or steward of DBS. The responsibilities that accompany "qualified ownership" occupied much of the planning process. These are still being developed in some areas (e.g., negotiation of intellectual property rights).

Incorporating the model of a "charitable trust" had implications for the viability of various uses of DBS for research. As a state government agency, MCDH is responsible for the protection and promotion of the public's health. This encompasses a variety of activities, including research that could benefit public health. The countervailing obligation is that DBS should not be used for research that has no potential to benefit public health. For example, use of DBS for research on non-medically useful cosmetic products is not consistent with MDCH's obligation as a trustee.

In addition to its obligation to allow research use of DBS only for studies that may potentially benefit the public's health, MDCH is also ethically and legally obligated to those whose blood samples are used for research purposes including following research regulatory requirements.

Principles of ethical research from the Belmont Report are respect for persons, beneficence, and justice. $^{14}$ Beneficence requires that the person whose blood is being used is not harmed, and that any possible benefits are maximized and harms minimized. Since BioTrust research only involves blood (and in some cases data) that has already been collected for other purposes, there is no physical risk but there are confidentiality risks. To address these concerns all directly identifying information is removed before DBS are sent for storage and they are labeled only with a barcode. Before a sample is released for research, the barcode is replaced with a new tracking number. This practice removes the researcher from the original identifying information, which is retained only by the MDCH newborn screening program.

Justice requires fairness in who ought to receive the benefits of research and bear its burdens. The research pool is, theoretically, the entire population of Michigan-born children, so any potential burden that results from the research is unlikely to be borne by any one person or group. In addition, research that may disparage certain populations would not be allowed. MDCH's role as a trustee requires that any potential benefit from the research should extend to the populations from which the samples were collected. Therefore, research using Michigan dried blood spots should not be allowed if those contributing samples to the BioTrust are unlikely to be among the eventual beneficiaries. The National Research Council stated, "In population studies, benefit to the population has 
become one of the critical issues in determining the ethical justification for the study itself, and sharing benefits with the population is critical in preventing exploitation."15

In contrast to beneficence and justice, respect for persons was a more difficult consideration. Respect for persons requires that individuals be treated as autonomous agents. To address this principle consent was debated extensively. Ultimately it was determined that signed consent of a parent or legal guardian for subsequent research use would be required (but not for newborn screening itself), after October 1, 2010. Once a child becomes a legal adult at age 18, he or she can exclude their DBS from research. The MDCH Institutional Review Board (IRB) granted a waiver of consent for DBS that were already being stored before May 1, 2010, primarily based on the impracticability of obtaining consent for some 4 million DBS going as far back as 1984 .

Although DBS may be stored for potential research, IRB review is still required to ensure protection of human research subjects. In addition, anyone can request that his or her blood, or the blood of his or her child, not be used for research purposes and it will not be used. For those samples collected prior to October 1,2010 , there are educational campaigns in local venues and the media to inform Michigan citizens of the BioTrust project and their ability to exclude their DBS from research. There is a project website ${ }^{16}$ with exten- sive information about the BioTrust, including prior and forthcoming research.

Several layers to protect public and individual interests are incorporated into the Michigan BioTrust's structure, as illustrated below in Figure 1.

First, MDCH has established a Community Values Advisory Board to represent Michigan citizens, ${ }^{17}$ and provide guidance on overarching policies, including the types of research that would be seen as proper by Michigan laypeople. Second, a Scientific Advisory Board reviews the scientific merit of all research proposals. Third, IRBs conduct reviews both at $\mathrm{MDCH}$ and at the institution where the research is to be conducted. The MDCH IRB reviews proposals not only for compliance with regulations governing research, but also for concerns related to groups, not just individuals. Concerns might include research that certain populations may find morally objectionable or research that could disparage, embarrass, or conflict with cultural mores of certain groups. Finally, the BioTrust can decide whether or not the proposed research is a worthy use of a non-renewable resource.

\section{Conclusion}

Consistent with ethical principles, public health agencies must often balance the common good and individual rights when exercising their authorities. Concerning the Michigan BioTrust, this means balancing the public benefit from research using DBS with fair treat-

Figure I

\section{Michigan BioTrust for Health Governance/Advisory Structure}

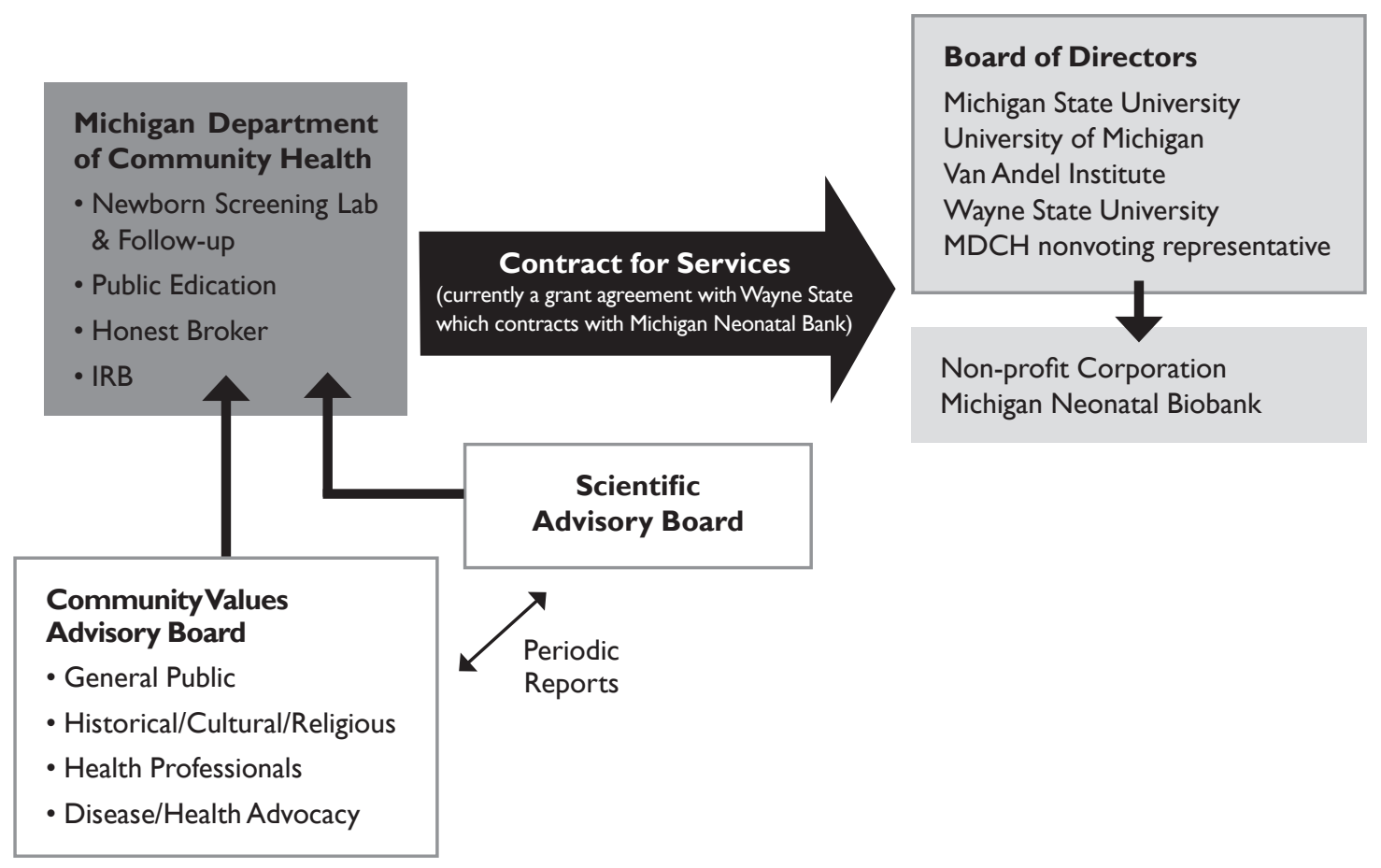


ment and respect for individuals' autonomy. Michigan's effort involved over two years of planning. The notion of storing DBS indefinitely for possible future research was first recommended in 1999 by the Governor-appointed Michigan Commission on Genetic Privacy and Progress. ${ }^{18}$ Since then, staff, experts, and community members have invested countless hours to develop the Michigan BioTrust for Health. These individuals continue to evaluate, develop, and refine the process and related aspects to meet objectives and respond to new developments. These efforts have led to substantial support and minimal opposition or complaints to prior and ongoing research involving DBS specimens in Michigan.

Our hope is that other states can benefit from Michigan's experience in exploring and developing opportunities for using DBS. We advise other jurisdictions to proceed thoughtfully to develop these opportunities, to listen respectfully to others, to take the time necessary to identify, weigh and balance interests, and to educate the public about the purposes of public health research and protections for individuals.

\section{Note}

The opinions in this article do not necessarily represent the views of the State of Michigan or the Michigan Department of Community Health.

\section{References}

1. For more information about Michigan Neonatal Biobank, visit 〈http://www.mnbb.org〉 (last visited December 15, 2010).

2. For more information about Michigan's newborn screening program, visit 〈http://www.michigan.gov/newbornscreening> (last visited December 15, 2010).

3. Michigan Public Health Code, M.C.L. 333.5431(7)(b).

4. D. E. Winickoff and R. N. Winickoff, "The Charitable Trust as a Model for Genomic Biobanks," New England Journal of Medicine 349 (2003):1180-1184, available at <http://www.nejm. org/doi/full/10.1056/NEJMsb030036> (last visited December 15, 2010).

5. M.C.L .333.1101 et seq.

6. M.C.L. $333.5431(7)(b)$.
7. M.C.L. 333.2226(a); MCL 333.2611; M.C.L. 333.2621; M.C.L. $333.5412(2)$

8. Moore v California Regents, 51 Cal. 3d 120 (1990), available at 〈http://www.eejlaw.com/materials/Moore_v_Regents_T08. pdf>.

9. Greenberg v Miami Children's Hosp, 264 F. Supp .2d 1064 S.D. Fla. (2003), excerpts from opinion available at $<\mathrm{http}$ ://indylaw.indiana.edu/instructors/orentlicher/healthlw/Greenberg. htm>.

10. Washington University v Catalona, 490 F. 3d 667 8th Cir. (2006), available at <http://prostatecure.wustl.edu/ pdf/8thCircuitOpinion.pdf> (last visited December 15, 2010).

11. 45 C.F.R. $\$ 46.116$ (8). (2009).

12. 45 C.F.R. Part 46 (2009); 21 C.F.R. Part 50 (2010); 21 C.F.R. Part 56 (2010).

13. See Winickoff and Winickoff, supra note 4

14. The Belmont Report, Ethical Principles and Guidelines for the Protection of Human Subjects of Research, The National Commission for the Protection of Human Subjects of Biomedical and Behavioral Research (April 18, 1979), available at <http:// www.hhs.gov/ohrp/humansubjects/guidance/Belmont.htm> (last visited December 15, 2010).

15. See Winickoff and Winickoff, supra note 4, quoting, National Research Council, Committee on Genome Diversity, Evaluating Human Genetic Diversity (Washington, D.C.: National Academy Press, 1997).

16. See Michigan BioTrust for Health, available at $<\mathrm{http}: / /$ www. michigan.gov/biotrust> (last visited December 15, 2010).

17. Michigan's Community Values Advisory Board includes representatives from the following organizations/interests: American Cancer Society (Great Lakes Division), American Civil Liberties Union of Michigan, Arab Community Center for Economic and Social Services, Cristo Rey, Faith Access to Community Economic Development, Inter-Tribal Council, Michigan Association of Genetic Counselors, Health Law Attorney, March of Dimes (Michigan Chapter), MichBio, Michigan Council for Maternal \& Child Health, Michigan Developmental Disabilities Council, Michigan Environmental Council, Michigan Minority Health Coalition, Michigan Health and Hospital Association, Michigan Osteopathic Association, National Alliance on Mental Illness Michigan, Newborn Screening Parent.

18. "Michigan Commission on Genetic Privacy and Progress Final Report and Recommendations," February 1999, available at <http://www.michigan.gov/documents/GeneticsReport_11649_7.pdf> (last visited December 15, 2010). 